\title{
Pengaruh Meander dan Keamanan Lereng Terhadap Kejadian Longsor di Jalan Raya Prupuk-Bumiayu (km 115+50 - 115+900)
}

\section{The Effect of Meander and Security Safety to The Landslide Events in The Prupuk- Bumiayu Main Road (km 115+50 - 115+900)}

Teguh Marhendi

Program Studi Teknik Sipil, Universitas Muhammadiyah Purwokerto

\section{Informasi Makalah}

Dikirim 13 Desember , 2017

Diterima, 22 Maret , 2018

\section{Kata Kunci: \\ Tingkat keamanan lereng, Jalan Prupuk-Bumiayu}

\begin{abstract}
INTISARI
Jalan Prupuk-Bumiayu pada segmen Ciregol (Km 115+50 - 115+900) berada pada perbukitan dengan ketinggian dari dasar tebing di atas Sungai Pedes sekitar $40 \mathrm{~m}$ dan diapit oleh dua sungai besar yaitu Sungai Glagah dan Sungai Pedas. Posisi aliran meandering pada dasar tebing ini dianggap mampu memberikan kontribusi terhadap kejadian longsoran di jalan Ciregol. Penelitian ini dimaksudkan untuk mengkaji tingkat keamanan lereng pada Km 115+50 - 115+900 jalan Raya Prupuk-Bumiayu, Ciregol Brebes Jawa Tengah. Pada kajian ini dilakukan penenlitian perhitungan kemanan lereng menggunakan metode Fellinius dengan memperhatikan pengaruh hujan dan aliran pada bagian dasar meander Sungai Pedes yang berhubungan langsung dengan bidang longsor. Hasil penelitian ini menunjukkan bahwa 1) keamanan lereng sesuai kondisi pada saat terjadi longsor adalah tidak aman dengan nilai keamanan (F) sebesar $0,749<1,2)$ debit (Q) yang terjadi pada meander sungai berdasarkan analisis data hujan menggunakan model Mock adalah sebesar 2,4 m3/dt dengan kecepatan aliran (V) sebesar 0,6 m/dt, dan terlalu kecil untuk mempengaruhi longsor pada dasar tebing
\end{abstract}

\section{Keyword:}

Landslides

Slope safety

Prupuk-Bumiayu road

Ciregol cross section

\begin{abstract}
Prupuk-Bumiayu road at Ciregol cross section (Km. 115+50-115+900) was $40 \mathrm{~m}$ head from Pedes River base and enclosed by Glagah and Pedes River.The research aim to study slope safety at Prupuk-Bumiayu road at Ciregol cross section. This study will focus to Fellinius Method with precipitaion influence and velocity consideration to avalanche calculation. The result of research shown that the slope safety at Prupuk-Bumiayu road at Ciregol cross section is $0,749<1$ safety value, so must to be landslides land. Second, water discharge on current events, is 2,4 cubic meter per second, and so this value of water discharge not influence to landslides at PrupukBumiayu road at Ciregol cross section.
\end{abstract}

\section{Korespondensi Penulis:}

Penulis Ke-1

Program Studi Teknik Sipil, Fakultas Teknik dan Sains

Universitas Muhammadiyah Purwokerto

Jl Raya Dukuhwaluh Purwokerto

Email: tmarhendi@gmail.com, teguhmarhendi@ump.ac.id

\section{PENDAHULUAN}

Kejadian longsor di Jalan Prupuk-Bumiayu, tepatnya di Ciregol Bumiayu sudah beberapa kali terjadi. Tanggal 11 April 2015 yang lalu, kejadian serupa terjadi pada titik lokasi longsor di Ciregol (Km 
115+50 - 115+900) dengan ketinggian tebing mencapai sekitar $40 \mathrm{~m}$ dari dasar tebing dengan panjang longsoran sekitar 72,1 m.

Berdasarkan pengamatan lapangan, lokasi longsor tebing, pada bagian bawah tebing tepat berhubungan dengan tikungan/meander Sungai Pedes. Kondisi tebing yang cenderung vertikal serta terbatasnya bidang gelincir, menyebabkan potensi longsoran sangat besar. Hal inilah yang mendorong pentingnya mengetahui faktor yang mendukung terjadinya longsor pada lokasi tersebut.

Penelitian ini difokuskan pada analisis perilaku Sungai Pedes pada meandering (tikungan) dibawah tebing, terkait dengan mekanisme aliran, analisis banjir sungai dan kejadian longsor tebing. Tujuan dari kajian ini adalah untuk menganalisis perilaku Sungai Pedes pada sisi meandering sungai terhadap erosi pada bagian bawah tebing. Kejadian longsor pada tebing di Km 115+50 - 115+900, dengan tinggi tebing longsor sekitar 40 m dengan panjang longsoran sekitar 72,1 m, menyebabkan sebagian jalan ambles dan masuk ke sungai. Di samping itu, kondisi hujan pada saat terjadi longsor tebing, perlu dikaji lebih mendalam apakah memberikan konribusi terhadap longsor tebing tersebut. Demikian juga dengan situasi meandering pada bagian bawah longsoran, juga perlu di analisis, apakah aliran dan kecepatan aliran pada meander tersebut memberikan kontribusi pada kejadian longsor terbut. Oleh karena itu perlu dikaji terkait mekanisme aliran pada meandering tersebut serta perilaku banjir dan sifat hujan pada DAS setempat dan hubungannya dengan kejadian longsor pada saat itu.

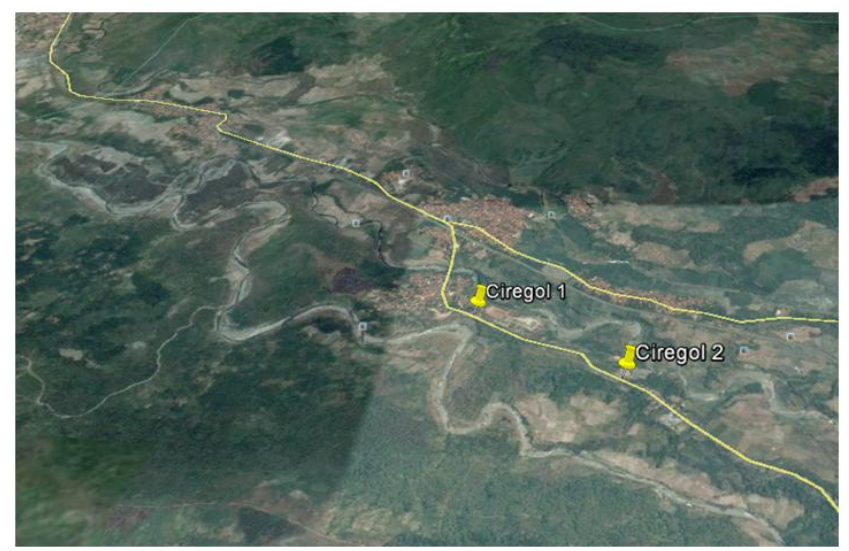

Gambar 1 Kondisi Tampak Atas dua sungai yang mengapit Jalan Prupuk-Bumiayu pada Segmen Ciregol (Km 115+50 - 115+900), (Google-earth, 2015)

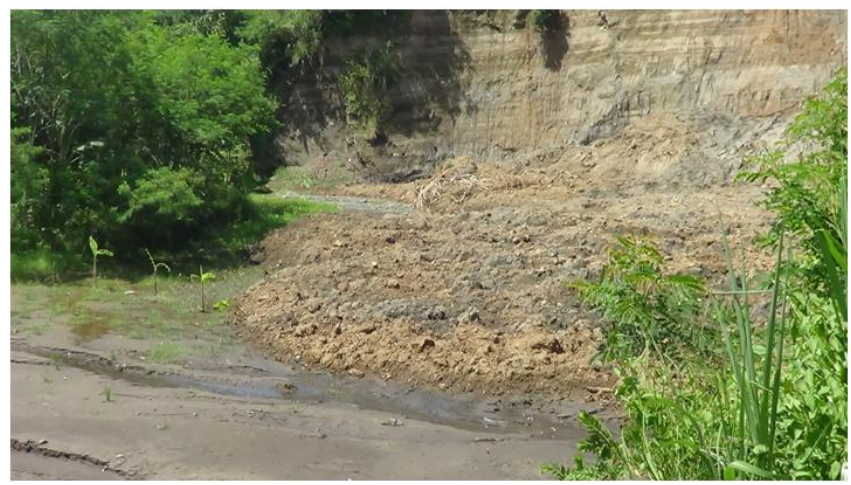

Gambar 2. Posisi Dasar Tebing Longsor Ciregol dan Dasar Sungai Pedes Pasca Longsor April 2015

(Dokumentasi, 2015)

\section{METODOLOGI PENELITIAN}

\section{Lokasi Penelitian}

Lokasi penelitian berada pada Jalan Raya Prupuk-Bumiayu, Ciregol, Kutamendala, Tonjong, Brebes pada Km 115+50 - 115+900 dengan panjang longsoran \pm 72,1 m dengan kedalaman $\pm 40 \mathrm{~m}$. 
Penentuan lokasi ini dilakukan dengan penentuan sampel lokasi melalui metode survey dengan kriteria metode area sampling. Penentuan lokasi dilakukan dengan metode isindental pada lokasi Jalan Raya PrupukBumiayu, Ciregol, Kutamendala, Tonjong, Brebes pada Km 115+50 - 115+900. Lokasi ini dipilih karena kejadian longsor terjadi pada segmen ini.

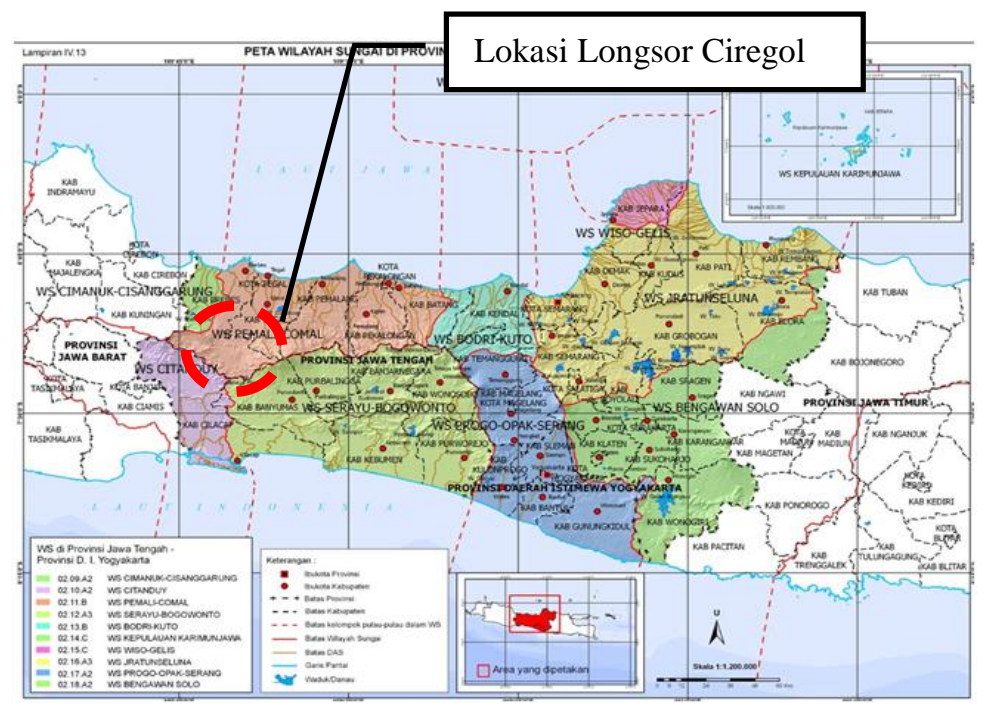

Gambar 3. Lokasi Longsor tebing Ciregol berdasar Peta Rupa Bumi Indonesia

Data dan Alat Penelitian

1. Data Primer

Data primer dalam penelitian ini berupa :

1) Pengukuran profil Sungai Pedes pada Segmen meandering longsoran

2) Pengukuran tanah (mekanika tanah dan sifat tanah)

2. Data Sekunder

Data sekunder dalam penelitian ini meliputi:

1) Data curah hujan harian dan bulanan

2) Data debit banjir tahunan

3) Peta DAS setempat

3. Alat Penelitian

Alat-alat dalam penelitian ini meliputi:

1) Alat pengukuran langsung pada penelitian sungai (disediakan)

2) Alat pengukuran tanah (tersedia di Lab Teknik Sipil)

3) Komputer dan model analisis terkait

4) Kendaraan

5) Pendukung lain 
4. Langkah-Langkah penelitian

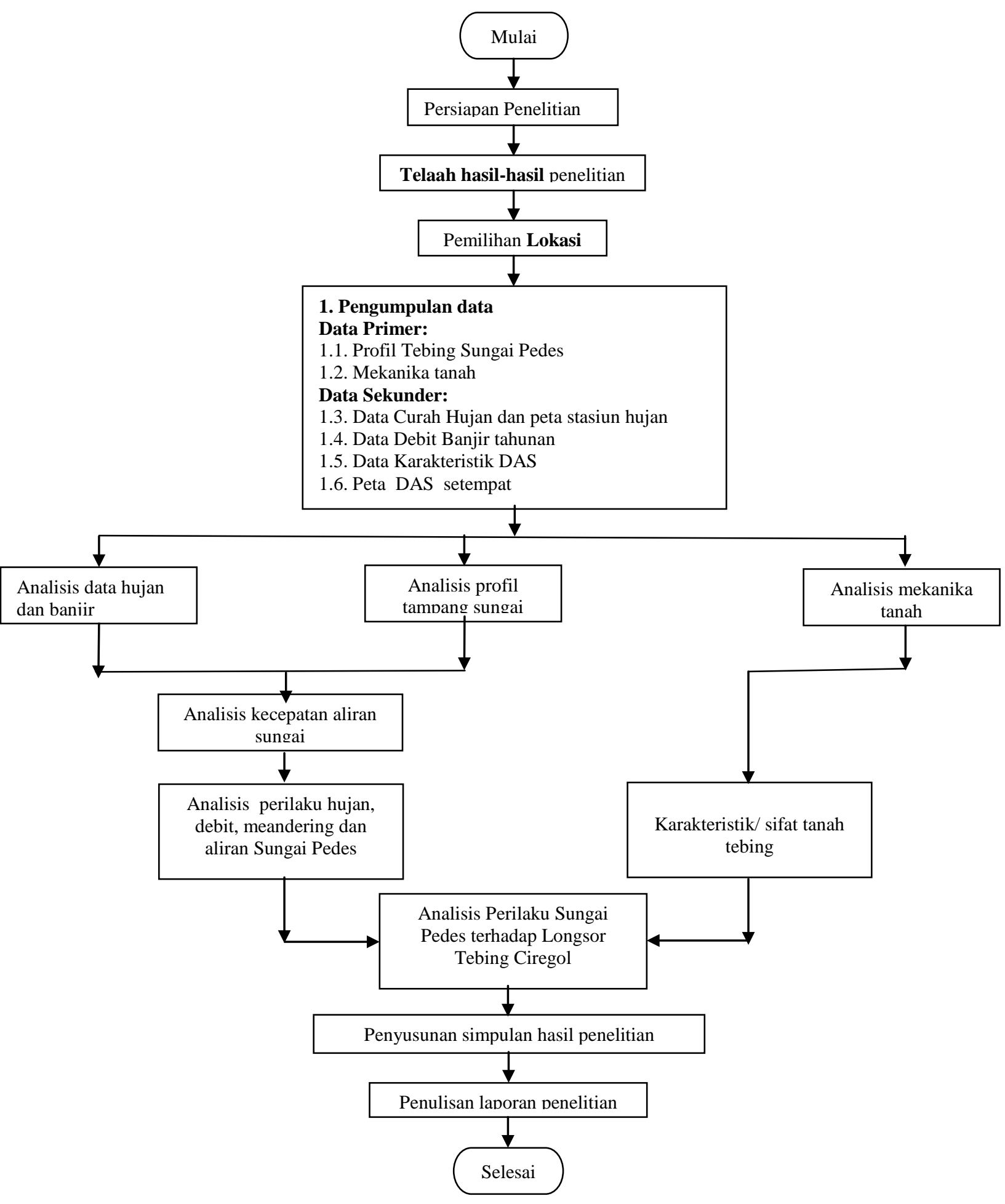

Gambar 4. Langkah-Langkah Penelitian 


\section{HASIL DAN PEMBAHASAN}

1. Kondisi Km. 115+50 - 115+900 Ruas Jalan Prupuk-Bumiayu

Jalan Prupuk-Bumiayu pada segmen Ciregol terletak pada ketinggian dari dasar tebing di atas Sungai Pedes sekitar $40 \mathrm{~m}$. Jalan ini diapit oleh Sungai Glagah dan Sungai Pedas. Pada posisi longsoran, morfologi kedua sungai berbentuk meandering), dan pada beberapa sisi kelokan sungai menggerus tepian dasar tebing jalan atau mengalami erosi tebing sungai (under cut slope) pada saat aliran besar.

\section{Geologi Tanah Setempat}

Mengacu Iva Dwi Khoiroh, Teguh Marhendi, Amris Azizi (2014), batuan yang terdapat di ruas jalan Prupuk-Bumiayu didominasi oleh tuff kelabu muda dan batu pasir tufan, bersisipan konglomerat dan batu pasir magnetit serta tebalnya $150 \mathrm{~m}$. Batu pasir tufan dengan sisipan konglomerat inilah yang menjadi batuan dasar tebing sungai sehingga yang mudah terkikis/tererosi. (Dinas ESDM Kabupaten Brebes, 2010).

\section{Kondisi Hidrologi}

Berdasarkan data Dinas ESDM Kabupaten Brebes (2013), secara umum wilayah kecamatan tonjong memiliki kisaran curah hujan sedang antara 1911- $4325 \mathrm{~mm} /$ tahun (data curah hujan dalam periode 12 tahun) dengan rerata berkisar antara 159,25 - 360,42 mm/tahun, dengan jumlah bulan hujan dalam setahun berlangsung 10-12 bulan.

Tabel 1. Analisis Curah Hujan Dalam Kurun Waktu 12 Tahun

\begin{tabular}{ccc}
\hline Tahun & $\begin{array}{c}\text { Hujan Per Tahun } \\
(\text { mm/tahun })\end{array}$ & $\begin{array}{c}\text { Hujan Rata-rata } \\
(\text { mm/tahun })\end{array}$ \\
\hline 2003 & 2393 & 199.42 \\
2004 & 2395 & 199.58 \\
2005 & 2488 & 207.33 \\
2006 & 2523 & 210.25 \\
2007 & 2210 & 184.17 \\
2008 & 1509 & 125.75 \\
2009 & 2397 & 199.75 \\
2010 & 4325 & 360.42 \\
2011 & 1911 & 159.25 \\
2012 & 2293 & 191.08 \\
\hline
\end{tabular}

Sumber : Dinas ESDM Kab. Brebes, 2013, Iva Dwi Khoiroh, Teguh Marhendi, Amris Azizi (2014), analisis 2016

\section{Analisis Kemiringan Lereng}

Berdasarkan pengukuran tanah di lapangan diproleh data sebagai berikut: (Iva Dwi Khoiroh, Teguh Marhendi, Amris Azizi (2014) dan analisis tahun 2016).

\begin{tabular}{|c|c|}
\hline Berat jenis tanah $(\gamma)$ & $=16.48 \mathrm{Kg} / \mathrm{cm}^{3}$ \\
\hline Kohesi (c ) & $=0.16 \mathrm{Kg} / \mathrm{cm}^{2}$ \\
\hline Sudut geser dalam tanah $(\varphi)$ & $=14^{\circ}$ \\
\hline n lereng $(\beta)$ & $=51^{\circ}$ \\
\hline lereng $(H)$ & $0 \mathrm{~m}$ \\
\hline
\end{tabular}




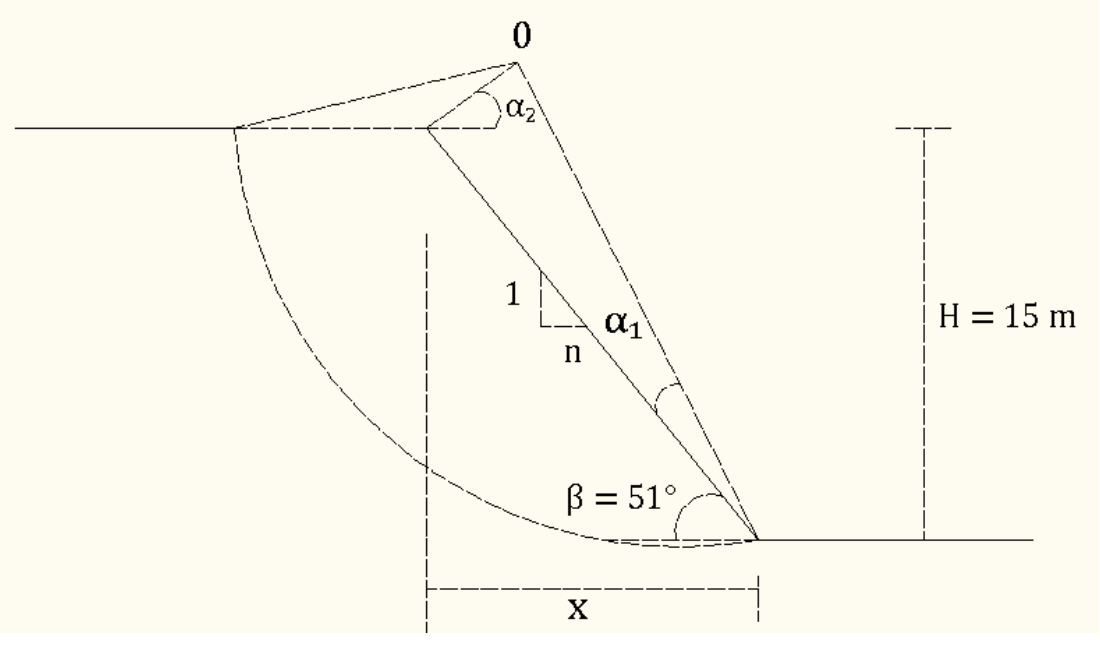

Gambar 5. Tinggi dan Kemiringan Lereng pada Km. 115+50 - 115+900 (Analisis, 2016)

Mengacu data kemiringan lereng tersebut, selanjutnya dilakukan perhitungan penentuan pias. Berdasarkan data sudut lereng dan tanah yang ada di dapat nilai $\mathrm{x}=44,44 \mathrm{~m}$ dan nilai $\mathrm{n}$ sebesar 0,9. Mengacu pada Tabel berikut maka diperoleh $\alpha 1=28^{\circ}$ dan $\alpha 2=37^{\circ}$.

Berdasarkan gambar potongan pada Gambar 4.5, maka panjang lingkaran gelincir $(\Sigma \mathrm{L})$ dapat dihitung adalah 51,50 m,. Mengacu Hardiyatmo (2002) maka untuk lingkaran longsor dibagi 6 pias dengan lebar pias ditentukan sebesar $\mathrm{bi}=51,50 / 6=8,53 \mathrm{~m}$ dan sisi miring pias, $a \mathrm{a}=\mathrm{bi} \cos \theta \mathrm{i}$

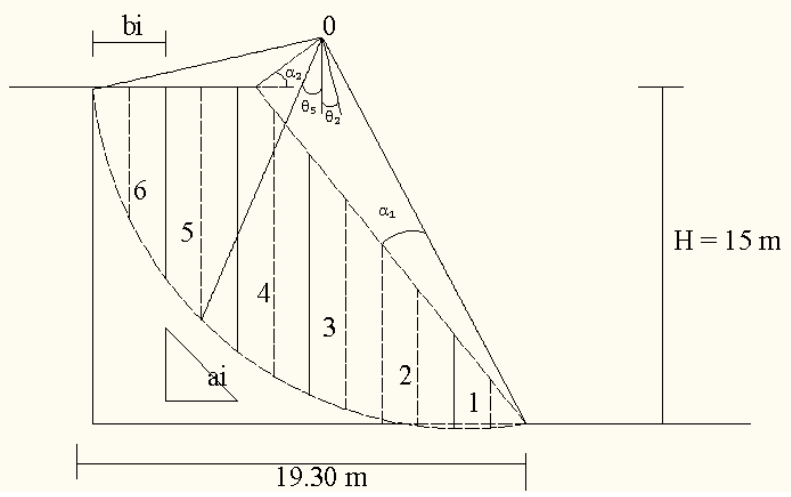

Gambar 6. Penentuan Pias Lereng pada Km. 115+50 - 115+900 (Analisis, 2016)

Berdasarkan potongan Gambar di atas, dilakukan perhitungan Angka Keamanan ( F ) untuk mengetahui tingkat keamanan pada lereng tersebut.

$$
\begin{aligned}
& \mathrm{F}=\frac{\sum_{i=1}^{i=n}\left(c \cdot a_{i}+N_{i} \operatorname{tg} \varphi\right)}{\sum_{i=1}^{i=n} W_{i} \cdot \sin \theta_{i}} \\
& \mathrm{~F}=0,749<1
\end{aligned}
$$

Berdasarkan perhitungan tersebut, maka dapat disimpulkan bahwa lereng saat itu dalam keadaan tidak stabil. 


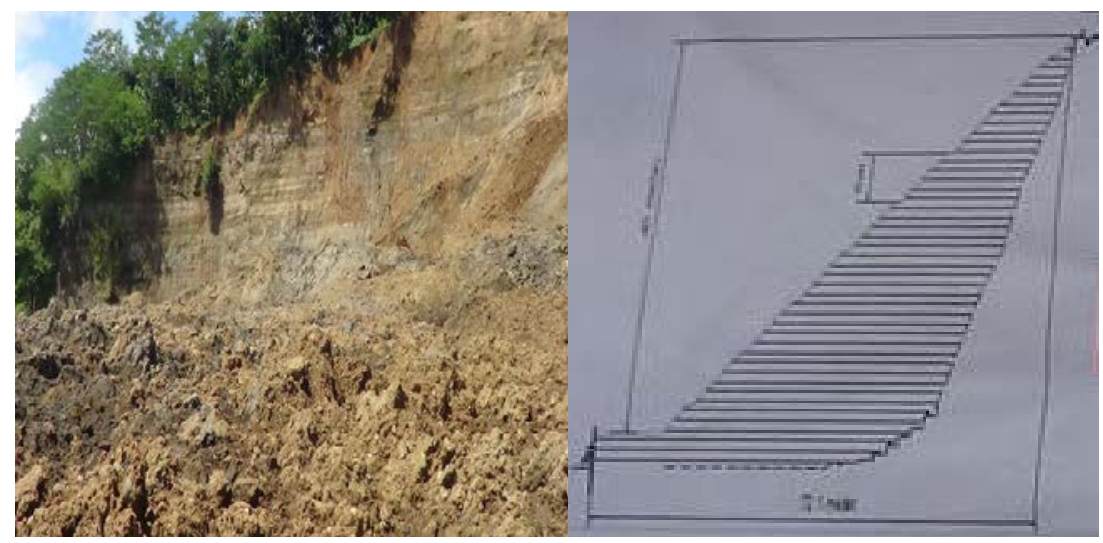

Gambar 7. Kondisi bagian dasar Tebing dan Sketsa Bidang Longsoran pada Lokasi Sumber: Dokumentasi, 2015, Kementrian PUPR, 2015

5. Analisis Hidrologi dan Hidraulika Aliran

Analisis dilakukan dengan model simulasi, mengingat data debit pada lokasi penelitian tidak tersedia, dalam hal ini analisis dilakukan menggunakan Model FJ. Mock (Sri Harto Br., 2000). Secara sederhana skema sistem Mock dapat disajikan pada Gambar 12 berikut ini.

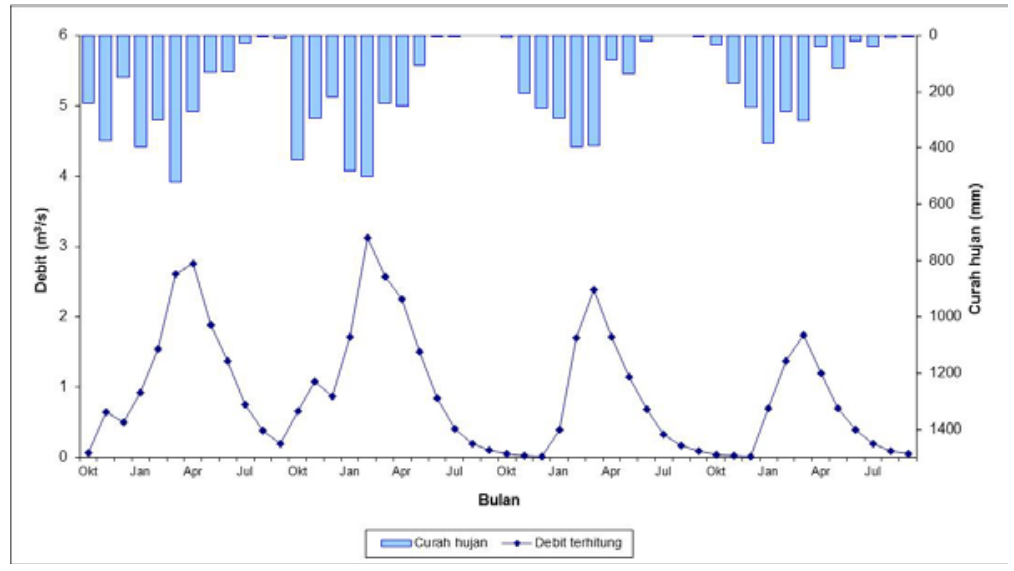

Gambar 8 Simulasi Debit andalan dengan Model Mock Sumber: Analisis, 2016

Berdasarkan analisis seperti Gambar 8, diketahui bahwa debit andalan sesuai perhitungan dengan Metode Mock, diketahui sebesar 2,4 m3/detik. Mengacu hasil pengukuran rerata tampang sungai pada posisi meander, diketahui bahwa lebar rerata sungai $8 \mathrm{~m}$ dengan kedalaman muka air rerata 0,5 m. Dengan data tersebut, dapat diketahui kecepatan pada posisi meander dengan debit 2,4 m3/dt dan luas tampang sebesar 4 $\mathrm{m} 2$ adalah $0,6 \mathrm{~m} / \mathrm{dt}$.

\section{KESIMPULAN}

Keamanan lereng sesuai kondisi pada saat terjadi longsor adalah tidak aman dengan nilai keamanan (F) sebesar 0,749<1, hal ini sebagai salah satu penyebab kejadian longsor pada dasar tebing Sungai Pedes. Debit (Q) yang terjadi pada meander sungai berdasarkan analisis data hujan menggunakan model Mock adalah sebesar 2,4 m3/dt dengan kecepatan aliran (V) sebesar 0,6 m/dt, dan terlalu kecil untuk mempengaruhi longsor pada dasar tebing. 


\section{DAFTAR PUSTAKA}

[1] Azizi, A., dkk., 2012, Analisis Kestabilan Lereng Kawasan Bencana Tanah Longsor Desa Binangun Kecamatan Banyumas, Laporan Penelitian Hibah Program Studi, LPPM Universitas Muhammadiyah, Purwokerto

[2] Dwikorita Karnawati, 2002, Pengenalan Daerah Rentan Gerakan Tanah dan UpayaMitigasinya, Makalah Seminar Nasional Mitigasi Bencana Alam Tanah Longsor, Semarang 11 April 2002, Semarang: Pusat Studi Kebumian Lembaga Penelitian Universitas Diponegoro

[3] Guzzetti, F., Cardinali, M., Reichenbach, P., Cipolla, F., Sebastiani, C., Galli, M. and Salvati, P., 2004. Landslides triggered by the 23 November 2000 rainfall event in the Imperia Province, Western Liguria, Italy, Engineering Geology, Vol. 73, pp. 229 - 245.

[4] Hardiyatmo, H.C., 2002, Mekanika Tanah 1, edisi ke-2, Beta Offset, Yogjakarta

[5] Hardiyatmo, H.C., 2002, Mekanika Tanah 2, edisi ke-2, Beta Offset, Yogjakarta

[6] Hasnawir, 2011, Intensitas Curah Hujan Memicu TanahLongsor Dangkal Di Sulawesi Selatan, Jurnal Penelitian Kehutanan Wallacea Vol.1 No.1, Agustus 2012:62-73

[7] Iva Dwi Khoiroh, Teguh Marhendi, Amris Azizi, 2014, Perbandingan Metode Fellinius dan Slope/W Untuk Analisis Stabilitas Lereng, Jurnal Techno Fakultas Teknik UMP Vol 15 No.2 Oktober 2014

[8] Kabul Basah Suryolelono, 2002, Bencana Alam Tanah Longsor Perspektif Ilmu Geoteknik, Pidato Pengukuhan Jabatan Guru Besar, Yogyakarta: Fakultas Teknik UGM

[9] Kuswaji Dwi Priyono, Yuli Priyana, dan Priyono, 2006, Analisis Tingkat Bahaya Longsor Tanah di Kecamatan Banjarmangu Kabupaten Banjarnegara Forum Geografi, Vol. 20, No. 2, Desember 2006

[10] Sutikno, dkk., 2001, Pengelolaan Data Spasial Untuk Penyusunan Sistem InformasiPenanggulangan Tanah Longsor di kabupaten Kulon Progo, Daerah Istimewa Yogyakarta, Makalah Seminar Dies Fakultas Geografi UGM ke-38 Tanggal 29 Agustus 2001, Yogyakarta: Fakultas Geografi UGM

[11] Yulvi Zaika, Syafi'ah, 2011, Pengaruh Beban Dinamis dan Kadar Air Tanah Terhadap Stabilitas Lereng Pada Tanah Lempung Berpasir, JURNAL REKAYASA SIPIL / Volume 5, No.1-2011ISSN 1978 5658 